\title{
AN IMPROVED MICROMETHOD FOR THE DETERMINATION OF ACETAMINOPHEN IN PLASMA BY VISIBLE SPECTROPHOTOMETRY: APPLICATION TO A PHARMACOKINETIC STUDY IN RABBITS
}

\author{
JOSE RAUL MEDINA*, ADELA LICEA, MARCELA HURTADO \\ Departamento Sistemas Biologicos, Universidad Autonoma Metropolitana-Xochimilco, Mexico City, Mexico \\ Email: rmlopez@correo.xoc.uam.mx
}

Received: 18 Apr 2017, Revised and Accepted: 14 Jun 2017

\begin{abstract}
Objective: To report a simple and economic alternative spectrophotometric micro-method for the determination of acetaminophen using $200 \mu$ l of plasma sample.

Methods: The analyses were based on a simple colorimetric test in which p-aminophenol, after an acidic hydrolysis step, is reacted with phenol in an alkaline medium to form an indophenol dye which exhibits a maximum extintion at 625 nm. The micro method was validated according to the international criteria, and then it was used for the quantification of plasma levels of acetaminophen after rectal administration of $100 \mathrm{mg}$ of the drug
\end{abstract} to male New Zealand rabbits.

Results: The analytical recovery was $100.97 \%$, with solutions of $5-25 \mu \mathrm{g} / \mathrm{ml}$ (plasma/water). The linearity with plasma solutions was good ( $\mathrm{R}^{2}=$ 0.995), at the same concentration levels. The within-run and between-run precision, as well as accuracy expressed as coefficient of variation, were less than $8 \%$. The mean accuracy was $102.24 \%$. The stability was proved for a one-week period at $-20{ }^{\circ} \mathrm{C}$. The pharmacokinetic parameters were computed by non-linear regression analysis. The non-compartment model analysis was used to fit the in vivo data.

Conclusion: The validation parameters were within acceptable limits for clinical studies. The analysis was adequate for the determination of acetaminophen in small plasma samples, and it can be easily adapted by any hospital or clinical laboratory with non-special equipment.

Keywords: Acetaminophen, NSAIDs, Pharmacokinetics, Rabbits, Spectrophotometric determination

(C) 2017 The Authors. Published by Innovare Academic Sciences Pvt Ltd. This is an open access article under the CC BY license (http://creativecommons.org/licenses/by/4.0/) DOI: http://dx.doi.org/10.22159/ijap.2017v9i4.19246

Acetaminophen (N-acetyl-p-aminophenol) is widely used in antipyretic and analgesic therapy. This compound is generally perceived to be a safe agent, but chronic abuse or acute overdose can lead to hepatotoxicity [1]. The analytical methods to monitor acetaminophen are especially important in the neonatal and paediatric population, or in small animals where samples are often difficult to obtain, and the blood volume is limited. An easy way to quantify acetaminophen is based on a simple colorimetric test in which p-aminophenol, after an acidic hydrolysis step, is reacted with phenol in an alkaline medium to form an indophenol dye [2, 3]. Some of the published colorimetric methods utilize more than $0.5 \mathrm{ml}$ of plasma or serum sample [3-6] so, laboratories that use analytical methods with limited plasma samples, could successfully perform the quantification of acetaminophen in paediatric population or in small laboratory animals. In this case, the sample volume should be as small as possible without causing damage to children, as a repeated blood sampling has been associated with neonatal anemia [7]. Previous researchers have reported, the spectrophotometric determination of some antihypertensive drugs in biological fluids using sulphonphthalein dyes [8], and the traces amount of acetaminophen in human plasma [9]. Our aim was to present an alternative micro method based on the indophenol reaction for the detection of acetaminophen in $200 \mu \mathrm{l}$ of plasma sample. It provides a simple and economical screening test to be used in the laboratory. The method was applied to the determination of acetaminophen in plasma samples arising from a pharmacokinetic study in rabbits. This animal model has been used for pharmacokinetic studies of antipsychotic agent [10]. In our work, New Zealand rabbits were employed, and plasma levels of acetaminophen were determined after administration of a rectal solution with the therapeutic dose of $100 \mathrm{mg}$ of the drug.

Acetaminophen was purchased from Sigma-Aldrich Co. (St Louis, MO, USA). Methanol, 25\% liquid $\mathrm{NH}_{3}$, concentrated $\mathrm{HCl}$, trichloroacetic acid, and phenol were analytical grade supplied by Merck-Mexico SA (Naucalpan, Mexico). The spectrophotometric apparatus was a Perkin Elmer UV/Vis Spectrometer Lambda 2S (Norwalk, CT, USA). The stock solution of acetaminophen $(1 \mathrm{mg} / \mathrm{ml})$ was prepared in methanol, and it was stored at $4{ }^{\circ} \mathrm{C}$ until use. Appropriate dilutions of acetaminophen were made in drug-free plasma to give final concentrations of $5,10,15,20$, and $25 \mu \mathrm{g} / \mathrm{ml}$. The concentration range of $10-20 \mu \mathrm{g} / \mathrm{ml}$ corresponds to commonly associated levels with antipyresis, after a single rectal dose of 25 $\mathrm{mg} / \mathrm{kg}[11,12]$. The procedure was adapted and validated from that reported by Frings and Saloom [3]. The determination consists in the reaction between p-aminophenol and phenol, in an alkaline medium to form an indophenol dye, which exhibits a maximum extinction at $625 \mathrm{~nm}$. The p-aminophenol is the hydrolysis product of acetaminophen and its metabolites, so by this way the total drug is quantified. Briefly, to an aliquot of heparinized plasma $(200 \mu \mathrm{l}$ of standard or sample), $200 \mu \mathrm{l}$ of $20 \%$ trichloroacetic acid was added. The high concentration of trichloroacetic acid was necessary to produce a solid precipitation of the plasma proteins. The constituents then were vortexed for $10 \mathrm{~s}$, and centrifuged at 5000 $\mathrm{rpm}$ for $10 \mathrm{~min}$. The supernatant was recovered, and $100 \mu \mathrm{l}$ of concentrated $\mathrm{HCl}$ was added. After vortexed again for $5 \mathrm{~s}$, the constituents were placed $35 \mathrm{~min}$ in a boiling water bath for hydrolysis, then $500 \mu \mathrm{l}$ of liquid $\mathrm{NH}_{3}$, and $400 \mu \mathrm{l}$ of $4 \%$ phenol were added. Finally, after 30 min acetaminophen was determined at $625 \mathrm{~nm}$.

The absolute recovery of acetaminophen from plasma was determined to analyze three standard calibration curves in plasma, and three standard curves in water. The absorbances of acetaminophen in plasma were related with the absorbances of acetaminophen in water by simple linear regression analysis. To evaluate linearity, the standards calibration curves were prepared by plotting absorbance vs. concentrations of acetaminophen in plasma. The slopes were determined using a linear least-square regression analysis. All results are expressed as mean \pm standard deviation (SD). The within-run precision of the assay was determined by the analysis of five plasma solutions, with different acetaminophen concentrations, by replicate $(n=3)$. The betweenrun precision of the method was evaluated by performing six standard curves in plasma using three different concentrations (low, medium, and high), over a range of $5-25 \mu \mathrm{g} / \mathrm{ml}$. The between-run 
precision was investigated during a four-week period $[13,14]$. The accuracy of the method was determined in plasma samples, containing acetaminophen with $5-25 \mu \mathrm{g} / \mathrm{ml}$, prepares by one person and assessed by another who had no knowledge of the concentrations. The samples were analyzed with respect to a standard calibration curve in plasma. The mean accuracy, 95\% confidence limits $\left(\mathrm{CI}_{95 \%}\right.$ ), and its coefficient of variation (CV) were calculated. The analytical results were also compared in a graph, in which the determined vs. known concentrations were plotted. To test stability, the spiked blank plasma samples at three different concentrations (low, medium, and high) were made and they were analyzed at the one-week period, after storing at $-20{ }^{\circ} \mathrm{C}$ performing replicates $(\mathrm{n}=3)$. The plasma concentrations of drug were determined with reference to a standard calibration curve, obtained by plotting the absorbances vs. known plasma concentrations of acetaminophen, prepared the same day of the analysis $[13,14]$. The method was applied in a pharmacokinetic study in rabbits. The animals were treated according to a protocol approved by the local Animal Ethics Committee (CICUAL. UAM-X.29), and following the Mexican federal regulations for the care and use of laboratory animals NOM-062-ZO0-1999 [15]. Six white male New Zealand rabbits (weight 3-4 kg) were used as an animal model. The animals fasted $12 \mathrm{~h}$ before the test. Before rectal administration, a $500 \mu \mathrm{l}$ of blood sample was withdrawn from the marginal vein of each animal to serve as a control. At zero time, rabbits were treated with an aqueous solution of acetaminophen in a single dose of $100 \mathrm{mg}$. After administration, $500 \mu \mathrm{l}$ of blood samples were taken at $0.25,0.5,1.0$, 1.5 , and $2 \mathrm{~h}$ and they were collected in heparinized polypropylene tubes. The plasma was separated by centrifugation and immediately frozen until their test according to the method described above. The pharmacokinetic parameters were computed by non-linear regression analysis using the WinNonlin version 2.1 (Parsight Corp. Palo Alto, CA, USA). The non-compartment model analysis was used to fit the in vivo data. Data are given as mean \pm standard error of the mean (SEM).

The analytical recovery was performed relating the absorbances of acetaminophen in plasma solutions, with respect to the absorbances of acetaminophen in water solutions, over a concentration range of 5-25 $\mu \mathrm{g} / \mathrm{ml}$. The slope of the regression line showed an average analytical recovery of $100.97 \%$, with $90.34-111.59 \%$ as $\mathrm{CI}_{95 \%}$. Three standard calibration curves of acetaminophen in plasma were made at different times over a two-week period. The mean slope of the absorbances vs. acetaminophen concentrations was $0.0133 \pm 0.001$ $\left(\mathrm{CV}=2.4 \%\right.$, and $\left.\mathrm{R}^{2}=0.995\right)$. The corresponding intercept was $-0.043 \pm 0.014$. The value of the intercept was not significantly different from zero, in any of the three standard calibration curves $\left({ }^{*} \mathrm{P}>0.05\right)$. The $\mathrm{CV}$ calculated to prove the within-run precision of the test, in five plasma solutions, was $0.74-2.89 \%$. The between-run precision was calculated from the slopes of six standards calibration curves, which were independently prepared. The CV of the slopes was $6.91 \%$. The mean accuracy of the method was $102.24 \%$, with 94.67-109.53\% as $\mathrm{Cl}_{95 \%}$, and $\mathrm{CV}$ of $7.77 \%$. When the determined vs. known acetaminophen concentrations were plotted, the regression equation was: $y=1.0211 x-0.101$, and $\mathrm{R}^{2}=0.994$. The values of the slope and intercept do not significantly differ from 1 and 0 , respectively $\left({ }^{*} \mathrm{P}>0.05\right)$. No significant differences were found in samples stored at $-20{ }^{\circ} \mathrm{C}$ during a one-week period $\left({ }^{*} \mathrm{P}>0.05\right)$. The time of stability test was adequate because in an emergency case, the plasma samples will be analyzed as soon as possible, and is not necessary to store the plasma samples for a long period of time.

By the acceptable precision and accuracy of the method, it was successfully used in a pharmacokinetic study with rabbits. A typical plasma concentration-time profile of acetaminophen, obtained after rectal administration of an aqueous solution, in a single dose of 100 $\mathrm{mg} / \mathrm{rabbit}$ is illustrated in fig. 1. Additionally, the mean pharmacokinetic parameters calculated with non-compartment model analysis are shown in table 1 . A moderate inter-individual variability was observed in the kinetic parameters.

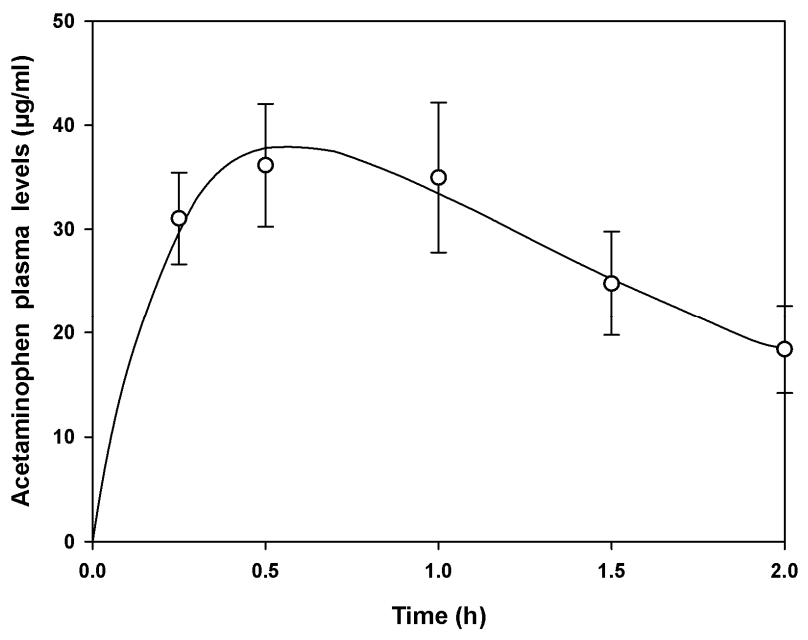

Fig. 1: Plasma concentration-time profile of acetaminophen (100 mg) following rectal administration of an aqueous solution to male New Zealand rabbits. mean \pm SEM, $n=6$

Table 1: Pharmacokinetic parameters calculated with non-compartment model analysis after rectal administration of acetaminophen (100 $\mathrm{mg}$ ) to rabbits

\begin{tabular}{llll}
\hline Parameter & Value & Parameter & Value \\
\hline $\mathrm{C}_{\max }(\mu \mathrm{g} / \mathrm{ml})$ & $39.24 \pm 6.05$ & MRT $(\mathrm{h})$ & $0.95 \pm 0.03$ \\
$\mathrm{~T}_{\max }(\mathrm{h})$ & $0.71 \pm 0.14$ & $\lambda_{\mathrm{z}}\left(\mathrm{h}^{-1}\right)$ & $0.64 \pm 0.08$ \\
$\mathrm{AUC}_{0 \rightarrow \mathrm{t}}(\mu \mathrm{gh} / \mathrm{ml})$ & $55.78 \pm 9.81$ & $\mathrm{t}_{1 / 2}(\mathrm{~h})$ & $1.21 \pm 0.20$ \\
\hline
\end{tabular}

AUC: area under the curve, MRT: mean residence time. mean \pm SEM, $n=6$

Some pharmacokinetic parameters calculated in this work agree with those reported by other researchers, e. $g$. the $\mathrm{C}_{\max }$ value of $39.24 \pm 6.05 \mu \mathrm{g} / \mathrm{ml}$ with the $C_{\max }$ value of $25 \mu \mathrm{g} / \mathrm{ml}$, found after rectal administration of a commercial suppository with $100 \mathrm{mg}$ of acetaminophen to rabbits [16]. Although it is the same dose used by us, our data is slightly higher due to acetaminophen was administered in an aqueous solution.

The colorimetric method described in this paper allows the quantitative determination of acetaminophen in plasma samples of $200 \mu \mathrm{l}$. The method is simple and economic. The validation parameters evaluated in this work were within acceptable limits for clinical studies. The method was applied to the analysis of plasma samples obtained from a pharmacokinetic study in rabbits. The test is suitable for monitor the plasma levels of acetaminophen, and it can be easily adapted by any hospital or clinical laboratory with non-special equipment.

\section{CONFLICT OF INTERESTS}

Declared none

\section{REFERENCES}

1. Gyamlani GG, Parik CR. Acetaminophen toxicity: suicidal vs accidental. Crit Care 2002;6:155-9.

2. Van Bocxlaer JF, Clauwaert KM, Lambert WE, De Leenheer AP. Quantitative colorimetric determination of urinary p-aminophenol with an automated analyzer. Clin Chem 1997;43:627-34.

3. Frings CS, Saloom JM. Colorimetric method for the quantitative determination of acetaminophen in serum. Clin Toxicol 1979;15:67-73.

4. Liu TZ, Oka KH. Spectrophotometric screening method for acetaminophen in serum and plasma. Clin Chem 1980;26:69-71. 
5. O'Connell SE, Zurzola FJ. A rapid quantitative determination of acetaminophen in plasma. J Pharm Sci 1982;71:1291-4.

6. Bailey ON. Colorimetry of serum acetaminophen (paracetamol) in uremia. Clin Chem 1982;28:187-90.

7. Koren G. Therapeutic drug monitoring principles in the neonate. Clin Chem 1997;43:222-7.

8. El-Didamoni AM, Hafeez SH, Saad AA. Extractionspectrophotometric determination of some antihypertensive drugs in pharmaceuticals and biological fluids using two sulphonphthalein dyes. Int J Appl Pharm 2015;7:10-7.

9. Bouchaib I, Mohamed S, El Mestafa EH, Sanae A, Taoufiq S. A statistical approach based on the total error concept for validation the bioanalytical method: application to the spectrophotometric determination of traces amount of acetaminophen in human plasma. Int J Pharm Pharm Sci 2014;6:413-21.

10. Dadhaniya T, Chaudhary K, Mehta P. Development of LC-MS method for determination of iloperidone in rabbit plasma: application to a pharmacokinetic study. Int J Pharm Pharm Sci 2015; 7:294-7.

11. Coulthard KP, Nielson HW, Schroder M, Covino A, Matthews NT, Murray RS, et al. Relative bioavailability and plasma paracetamol profiles of panadol suppositories in children. Aust Paediatr J 1998;34:425-31.

12. Birmingham PK, Tobin MJ, Henthorn TK, Fischer DM, Berkelhamer MC, Smith FA, et al. Twenty-four-hour pharmacokinetics of rectal acetaminophen in children: an old drug with new recommendations. Anesthesiology 1997; 87:244-52.

13. U. S. Food and Drug Administration. Guidance for Industry. Bioanalytical Method Validation; 2013. Available from: https://www.fda.gov/downloads/Drugs/Guidances/ucm3681 07.pdf. [Last accessed on 16 Apr 2017]

14. Rosing H, Man WY, Doyle E, Bult A, Beijen JH. Bioanalytical liquid chromatographic method validation. A review of current practices and procedures. J Liq Chromatogr Relat Technol 2000;23:329-54.

15. NORMA Official Mexicana NOM-062-ZO0-1999. Especificaciones técnicas para la producción, cuidado y uso de los animales de laboratorio; 1999. Available from: http://www.ibt.unam.mx/computo/pdfs/bioterio.NOM062.pdf. [Last accessed on 16 Apr 2017]

16. Tanaka Y, Kotaki H, Nakamura H, Uchino K, Iga T. Change of pharmacokinetic behavior of acetaminophen after discharge of suppository from rectum rabbits. Jpn J Hosp Pharm 1994;20:294-301.

\section{How to cite this article}

- José Raúl Medina, Adela Licea, Marcela Hurtado. An improved micromethod for the determination of acetaminophen in plasma by visible spectrophotometry: application to a pharmacokinetic study in rabbits. Int J Appl Pharm 2017;9(4):96-98. 